\title{
Internet addiction detection rate among college students in the People's Republic of China: a meta-analysis
}

\author{
Yao-jun Shao, Tong Zheng, Yan-qiu Wang, Ling Liu, Yan Chen and Ying-shui Yao*
}

\begin{abstract}
Background: With the development of economy and technology, the Internet is becoming more and more popular. Internet addiction has gradually become a serious issue in public health worldwide. The number of Internet users in China has reached 731 million, with an estimated 24 million adolescents determined as having Internet addiction. In this meta-analysis, we attempted to estimate the prevalence of Internet addiction among College Students in the People's Republic of China in order to improve the mental health level of college students and provide evidence for the prevention of Internet addiction.
\end{abstract}

Methods: Eligible articles about the prevalence of Internet addiction among college students in China published between 2006 and 2017 were retrieved from online Chinese periodicals, the full-text databases of Wan Fang, VIP, and the Chinese National Knowledge Infrastructure, as well as PubMed. Stata 11.0 was used to perform the analyses.

Results: A total of 26 papers were included in the analyses. The overall sample size was 38,245, with 4573 diagnosed with Internet addiction. The pooled detection rate of Internet addiction was 11\% (95\% confidence interval [Cl] 9-13\%) among college students in China. The detection rate was higher in male students (16\%) than female students (8\%). The Internet addiction detection rate was $11 \%(95 \% \mathrm{Cl} 8-14 \%)$ in southern areas, $11 \%(95 \% \mathrm{Cl} 7-14 \%)$ in northern areas, $13 \%(95 \% \mathrm{Cl} 8-18 \%)$ in eastern areas and $9 \%(95 \% \mathrm{Cl} 8-11 \%)$ in the mid-western areas. According to different scales, the Internet addiction detection rate was 11\% (95\% Cl 8-15\%) using the Young scale and 9\% (95\% Cl 6-11\%) using the Chen scale respectively. Cumulative meta analysis showed that the detection rate had a slight upward trend and gradually stabilized in the last 3 years.

Conclusion: The pooled Internet addiction detection rate of Chinese college students in out study was $11 \%$, which is higher than in some other countries and strongly demonstrates a worrisome situation. Effective measures should be taken to prevent further Internet addiction and improve the current situation.

Keywords: China, College students, Internet addiction, Meta-analysis, Prevalence

\section{Background}

Internet addiction can be defined as overuse of the Internet leading to impairment of an individual's psychological state (both mental and emotional), as well as their scholastic or occupational and social interactions [1]. Its symptoms generally include preoccupation, loss of control, high tolerance, withdrawal, craving, impairment of

*Correspondence: yingshuiyao@163.com

Faculty of Epidemiology and Statistics, School of Public Health, Wannan Medical College, 22 Wenchang West Road, Yijiang District, Wuhu 241002, Anhui, People's Republic of China function and a reduction in the ability to make decision [2]. The prevalence of Internet addiction in American college students is $12 \%$ and the Internet addiction rate of Iranian medical students is $10.8 \%$ [3, 4]. Worse yet, studies have shown that the rate of Internet addiction in Serbian schoolchildren is $18.7 \%$ [5]. In China, as well as worldwide, Internet addiction is a significant growing health problem in college students which is harmful to their physical and mental health. According to a survey conducted by the China Internet Network Information Center, the number of Internet users in China has 
reached 731 million, which equals the total population in Europe. There is no doubt that the Internet has brought us a lot of benefits. The Internet provides young people with good conditions for learning and strengthen the communication between young people. It is necessary for students to learn how to use the Internet. Internet tools can be effectively applied in school education, specifically in areas of lectures, assignments, real-time procedure demonstration, class discussion, and interaction with teachers. Internet can also realize the sharing of learning resources. So it is useful to integrate this learning modality with the traditional mode of teaching through a well thought out curriculum modification [6]. Besides, Internet has changed the way people socialize and it has become a medium for disease prevention and health promotion. Because young people are able to participate in a growing numbers of online communities providing support and advice for health care. A study of disturbed adolescents found that computer-mediated communication diminished certain traditional gender differences in group communication [7, 8]. However, the disadvantages caused by the Internet cannot be ignored. Internet addiction brings a lot of risks to society. Firstly, it makes people spend more time on Internet games and reduce normal social activities [9]. Secondly, there is a lot of unhealthy information on the Internet, such as pornography, violence and so on, which can affect people's mental health. The current findings suggest that adolescents with Internet addiction seem to have more aggressive dispositions than non-Internet addicted adolescents [10]. Finally, Internet addiction leads to lack of sleep, vision disturbances and decline in work efficiency, which are detrimental to our physical health [11]. Therefore, it is crucial for us to investigate the prevalence of Internet addiction among Chinese college students in order to provide epidemiological information to better understand and tackle this problem.

To the best of our knowledge, currently there is no consensus on the standard for the diagnosis and identification of Internet addiction disorder. Young's Internet Addiction Diagnostic Questionnaire (YDQ) was compiled in 1983. A respondent who answers yes to five or more of the eight questions is diagnosed as addiction Internet user. This questionnaire was further developed in 1998 by Young in order to incorporate the DSM-IV pathologic gambling criteria [12]. This 20-item scale, with its score ranging from 0 to 100 , is widely used in diagnosing Internet addiction. Respondent with the total score ranging from 50 to 79 is considered moderate Internet user and $80-100$ as severe Internet user with serious problems in Internet use. Previous studies have demonstrated that the scale has a high reliability and validity [12]. To take group differences into account, the
Chen Internet Addiction Scale (CIAS) is used to measure the extent of Internet addiction. There are 26 items in the CIAS, and an individual with a score of 68 or more is assessed as Internet addiction [13]. A revision of the CIAS with 19 questions was assembled by Bai in 2005, which divides Internet addiction into three level: normal (from 19 to 45), moderate (from 46 to 53) and excessive (above 53 ). These scales have been gradually used in Internet addiction research in China.

A lot of in-depth research on drug addiction has been explored, such as the epigenetic mechanisms of drug addiction. Unlike drug addiction, the influence of Internet addiction has been underestimated and few studies explore the mechanisms of it [14]. With the Internet addiction becoming more and more serious, relevant government departments begin to pay more attention to the effects of Internet addiction on teenagers and college students. Since their physical and mental development is not yet mature, their abilities of self regulation and control remain to be improved $[15,16]$. In this meta-analysis, we attempted to investigate the prevalence of Internet addiction among college students in the People's Republic of China in order to provide epidemiological evidence for the prevention of Internet addiction and finally improve the mental health level of college students.

\section{Methods}

\section{Search strategy}

Articles related to Internet addiction between 2006 and 2017 were retrieved from the Chinese periodical databases of Chinese National Knowledge Infrastructure, VIP and WanFang and from PubMed. We searched the following keywords: "Internet addition", "college students/ university students", "detection rate" and "China". Languages were restricted to English and Chinese. In addition, relevant articles were manually searched.

\section{Selection criteria}

Inclusion criteria included: the research objects are fulltime Chinese college students or vocational college students who are 18-25 years old; published between 2006 and 2017; using random sampling method; discussion of the Internet addiction detection rate in Chinese college students with reliable and clear statistics; Internet addiction is defined clearly and Internet addiction related questionnaire was adopted. CIAS has a Cronbach's alpha of 0.95 , and YDQ has a Cronbach's alpha of 0.93 as well as a good test-retest reliability $(r=0.85)[3,13]$; high quality articles have priority among the same subjects (For articles in which the same subjects were included in different publications, only the most recent or complete study was included). Exclusion criteria consisted of: articles unrelated to the purpose of the study; valid data cannot be 
extracted from the study; data is incomplete or repeated publication.

\section{Literature screening and quality assessment}

According to selection criteria, data extraction was completed independently by two researchers. Disagreements were solved by discussion or a third reviewer. For missing information, we contacted the correspondent authors for completed data. The following information was extracted from the literature: first author, year of publication, investigation time and area, sampling method, sample size, gender composition, and the scale used for Internet addition. Evaluation tools recommended by Agency for Healthcare Research and Quality (AHRQ) were used to measure the quality of research [17].

\section{Statistical analysis}

Stata 11.0 software was used for the analysis. According to the results of heterogeneity test, the random effects model was used. Subgroup analyses, cumulative metaanalysis and chart description were also performed. Begg's and Egger's test were applied to examine publication bias [18].

\section{Results}

\section{Basic information and quality assessment}

A total of 2551 articles were initially retrieved from the online Chinese periodical full-text Chinese National Knowledge Infrastructure $(\mathrm{n}=2033)$, VIP $(\mathrm{n}=214)$, Wan Fang $(n=107)$ databases, and from PubMed $(n=197)$. By reading the title 1653 articles were eliminated since the object of study was not college students or vocational college students, most of these articles instead are devoted to the study of middle school students. After quality evaluation, 765 articles were further excluded. Of these, 157 articles did not mention sampling method and 319 articles did not use random sampling method. Another 289 articles had no explicit standard of Internet addiction or a clear definition of Internet addiction. In addition, 107 articles were removed after reading the full text because of lacking necessary data or containing incomplete data. Finally, 26 articles were included. Figure 1 shows the literature search process. The total sample size was 38,245 college students, the largest sample was 4866 , and the smallest was 434.4573 students were diagnosed as Internet addiction. Main characteristics of the included 26 eligible articles are shown in Table 1.

\section{Meta-analysis of Internet addiction detection rates in college students in the People's Republic of China} A total of 26 articles reported Internet addiction detection rate among college students in China. Heterogeneity test showed a result of $\mathrm{I}^{2}=0.983$, indicating heterogeneous among studies. Therefore random-effects model was chosen. The pooled prevalence of Internet addiction in Chinese college students was $11 \%$ (95\% confidence interval [CI] 9-13\%), the result is shown by the forest plots in Fig. 2.

\section{Subgroup analyses}

In order to find the source of heterogeneity, subgroup analysis was performed according to stratum of gender, region, and scale. The result of subgroup analyses were presented in Table 2 . There is a statistically significant difference of the Internet addiction detection rates between male students and female students $(\mathrm{P}<0.05)$. The mean prevalence of Internet addiction was 16\% (95\% CI $13-19 \%)$ for male students and $8 \%$ (95\% CI 5-10\%) for female students respectively (Fig. 3). The Internet addiction detection rate was $11 \%$ (95\% CI 8-14\%) in southern areas, $11 \%(95 \%$ CI $7-14 \%)$ in northern areas, $13 \%(95 \%$ CI $8-18 \%)$ in eastern areas and $9 \%(95 \%$ CI $8-11 \%)$ in the mid-western areas. According to different scales, the Internet addiction detection rate was 11\% (95\% CI $8-15 \%)$ using the Young scale and 9\% (95\% CI 6-11\%) using the Chen scale.

\section{Cumulative meta-analysis}

Cumulative meta-analysis was carried out for the detection rate based on year and sample size. The detection rate had a slight upward trend and gradually stabilized around $12 \%$ in the past 3 years as shown in Fig. 4 . As for sample size,the detection rate grew more stable with the increase of sample size, also reaching $12 \%$.

\section{Publication bias}

Publication bias was assessed using the funnel plots (Fig. 5) [19]. Begg $(\mathrm{z}=0.44, \mathrm{P}=0.659)$ and Egger test $(t=-0.31, P=0.761)$ results suggested a low possibility of publication bias.

\section{Discussion}

The Internet has become an indispensable part of our lives, providing us more convenience. We rely heavily on the Internet, which also brings serious negative effects, such as game addiction. The influence of Internet addiction on college students as a special group has become a hot issue in public health. In this meta-analysis, 26 articles related to Internet addiction published between 2006 and 2017 were retrieved from databases based on our strict inclusion and exclusion criteria. As shown in Table 1, Internet addiction detection rates among college students in China varied widely from 4 to $43.9 \%$, possibly due to the sample sizes, economic development differences and time of investigation. Economic is more developed in eastern coastal areas of China than that in 


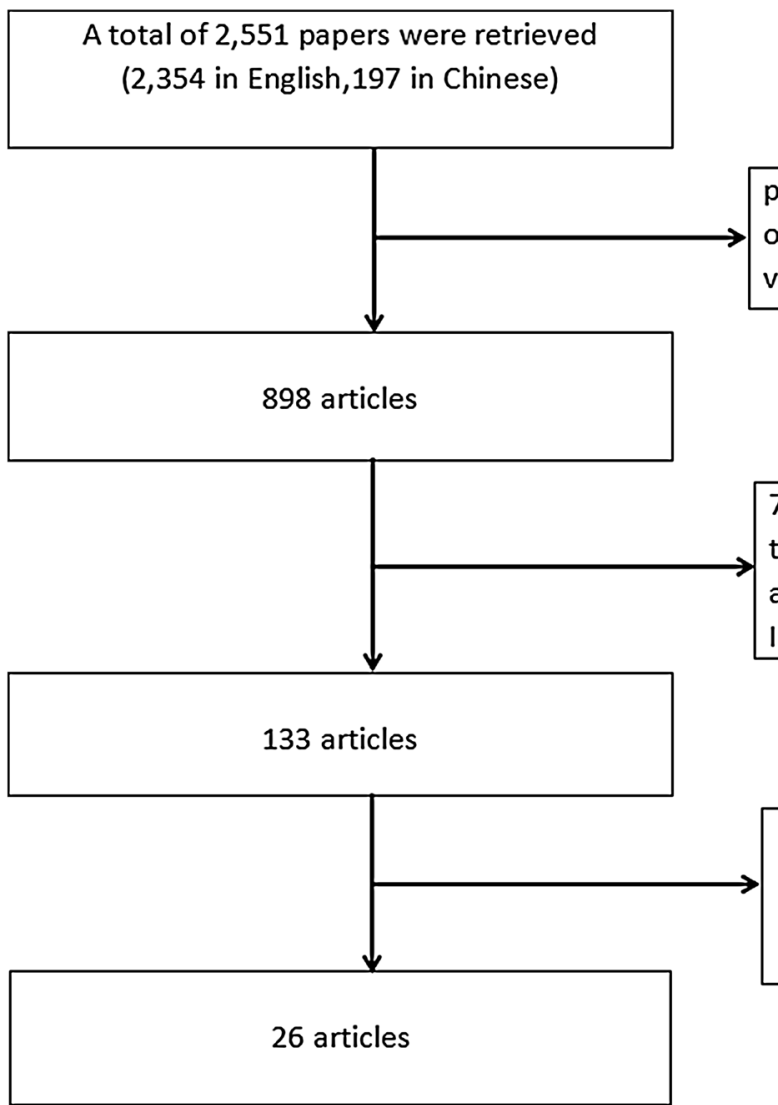

papers were eliminated because the object of study is not college students or vocational college students.(total 1,653)

765 articles were excluded because these articles are not random sampling, and there is no explicit standard of Internet addiction.

On reading the full text, papers

excluded comprised duplicated and incomplete data papers. (total 107)

Fig. 1 Flow chart of literature search

other areas, which results in earlier Internet touching among young people in east China. Currently, Internet has gradually become popular in east China. Since few people have been in contact with computer decades ago, low rate of Internet addiction was reported at that time. Our study reflects the general characteristics of Internet addiction prevalence among Chinese college students. A previous study proved that the rate of Internet addiction among teenagers in the world is $10 \%$ [20]. In our study, the pooled prevalence of Internet addiction in Chinese college students is $11 \%$ (95\% CI 9-13\%), which is similar to many studies conducted in China but different from studies conducted abroad. Compared with other countries, the detection rate in China is higher than Japan [21] (3.7\%) and Italy [2] (4.3\%), but similar to Pakistan [22] (16.7\%), Chile [12] (11.5\%) and Turkey [23] (9.7\%).

After subgroup analyses, we find that Internet addiction has different effects on male and female students, with higher detection rates in male students (16\%) than in female students (8\%). It may be explained by the differences in coping styles when facing life stress or negative life events. Male students tend to solve problems on their own and are reluctant to communicate with others or ask for help, leading to the low utilization of social support [24]. Some studies report that males are more sensitive to the Internet than females [25]. Compared with females, online games are more attractive to males who have a greater breadth of Internet use and more time surfing on Internet [26]. The above factors may contribute to a higher detection rate in male students. In terms of the regional factor, the Internet addiction detection rate was $11 \%$ in northern and southern areas in China. A higher detection rate was seen in the eastern areas as compared with mid-west. The regional difference could be caused by uneven economic development between eastern and mid-west areas, with more popularity of the Internet in the eastern areas attracting more college students. Our findings show that the Internet addiction detection rate using the Young scale was higher than that using the Chen scale. These two scales are widely used in the measurement of Internet addiction, and further research should be made to compare and evaluate the two scales.

According to the results of cumulative meta-analysis, the Internet addiction detection rate of Chinese college students has increased slowly since 2008 and gradually stabilized around $12 \%$ in the past 3 years. This shows that 
Table 1 Main characteristics of studies showing Internet addiction detection rates among college students in China

\begin{tabular}{|c|c|c|c|c|c|c|c|}
\hline \multirow[t]{2}{*}{ References } & \multirow[t]{2}{*}{ Years } & \multirow[t]{2}{*}{ District } & \multicolumn{3}{|c|}{ Prevalence of Internet addiction (\%) } & \multirow[t]{2}{*}{ Scale } & \multirow[t]{2}{*}{ Subject } \\
\hline & & & Total (IA/sample size) & Male (IA/sample size) & $\begin{array}{l}\text { Female (IA/sample } \\
\text { size) }\end{array}$ & & \\
\hline Yao et al. [34] & 2006 & Wuhu & $12.9(260 / 2010)$ & $16.1(229 / 1427)$ & $5.3(31 / 583)$ & Young scale & College studer \\
\hline Feng et al. [35] & 2007 & Guizhou & $8.4(126 / 1497)$ & $11.1(75 / 675)$ & $6.2(51 / 822)$ & Young scale & College student \\
\hline Wang et al. [36] & 2007 & Dalian & $7.3(70 / 954)$ & & & Young scale & College student \\
\hline Chen and Fan [37] & 2008 & Hefei & $4(28 / 705)$ & $6(22 / 364)$ & $1.8(6 / 341)$ & Young scale & College student \\
\hline Gao et al. [38] & 2008 & Changchun & $7.8(96 / 1227)$ & $12.7(51 / 403)$ & $5.5(45 / 824)$ & Young scale & College student \\
\hline Zhang et al. [39] & 2009 & Ningbo & $11.7(119 / 1014)$ & $18.1(108 / 597)$ & $2.6(11 / 417)$ & Young scale & College student \\
\hline Liu et al. [40] & 2009 & Wuhan & $4.6(20 / 434)$ & $7.3(15 / 207)$ & $2.2(5 / 227)$ & Young scale & College student \\
\hline Gao and Ma [41] & 2009 & Hangzhou & $11.9(81 / 683)$ & $16.7(51 / 306)$ & $8(30 / 377)$ & Young scale & College student \\
\hline Ju-Yu Yen et al. [42] & 2009 & Taiwan & $12.3(246 / 1992)$ & $19.1(111 / 581)$ & $9.6(135 / 1411)$ & CIAS & College student \\
\hline Zhou et al. [43] & 2010 & Daqing & $10.8(85 / 787)$ & $18.6(44 / 237)$ & $7.5(41 / 500)$ & Young scale & College student \\
\hline Zhang et al. [44] & 2011 & Dali & $10.4(100 / 965)$ & $13.6(46 / 338)$ & $8.6(54 / 627)$ & Young scale & College stude \\
\hline Zhao et al. [45] & 2012 & Lanzhou & $11.1(200 / 1807)$ & $13.5(125 / 926)$ & $8.5(75 / 881)$ & Young scale & College student \\
\hline Chen et al. [46] & 2012 & Wuhan & $6.8(32 / 470)$ & $11.1(20 / 181)$ & $4.2(12 / 289)$ & CIAS & College student \\
\hline Zhang et al. [47] & 2013 & Jinan & $5.5(52 / 853)$ & $11.4(32 / 280)$ & $3.5(20 / 573)$ & CIAS & College student \\
\hline Luo et al. [25] & 2014 & Shandong & $4.5(46 / 1026)$ & $8.1(31 / 384)$ & $2.3(15 / 642)$ & Young scale & College stude \\
\hline Zhang [48] & 2014 & Xinjiang & $8.7(90 / 1037)$ & & & CIAS & College student \\
\hline Zhou et al. [49] & 2014 & Wuxi & $12.8(621 / 4866)$ & $15.9(338 / 2122)$ & $10.3(283 / 2744)$ & Young scale & College student \\
\hline Luo and Zhu [50] & 2015 & Jiangxi & $7.2(39 / 545)$ & $16(19 / 119)$ & $4.7(20 / 426)$ & Young scale & College student \\
\hline Wang et al. [51] & 2015 & Hainan & $33.4(781 / 2341)$ & $38.4(312 / 812)$ & $30.7(469 / 1529)$ & Young scale & College student \\
\hline Zhang et al. [52] & 2015 & Nantong & $10.8(450 / 4168)$ & $12.2(185 / 1515)$ & $10(265 / 2653)$ & CDC standard & College student \\
\hline Zhou et al. [24] & 2015 & Yan'an & $19.5(117 / 601)$ & $27.6(48 / 174)$ & $16.2(69 / 427)$ & Young scale & College student \\
\hline Cong et al. [53] & 2016 & Yantai & $43.9(249 / 567)$ & $55.2(95 / 172)$ & $39(154 / 395)$ & Young scale & College student \\
\hline Chi et al. [54] & 2016 & Hefei & $15.2(178 / 1173)$ & & & Young scale & College student \\
\hline Chen et al. [55] & 2016 & Hebei & $9.6(234 / 2451)$ & $13.5(162 / 1204)$ & $5.8(72 / 1247)$ & CIAS & College student \\
\hline Wu et al. [56] & 2017 & Taishan & $6.7(93 / 1385)$ & $9.1(36 / 394)$ & $5.8(57 / 991)$ & Young scale & College student \\
\hline Li et al. [57] & 2017 & Henan & $6(160 / 2687)$ & $8.6(93 / 1087)$ & $4.2(67 / 1600)$ & Young scale & College student \\
\hline
\end{tabular}

CDC Chinese Center for Disease Control and Prevention, CIAS Chen Internet Addiction Scale, IA Internet addiction, Young Young Internet Addiction Scale

the Internet addiction has become an increasingly serious problem which can lead to many negative effects on college students, including physical and mental health. Internet addicts are more obvious in obsessive-compulsion, interpersonal sensitivity, depression, anxiety, hostility and other problems. Their mental health level is lower because they are addicted to the Internet for a long time which results in the lack of interpersonal communication, which in itself is a risk factor for mental illness [24]. Furthermore, Internet addiction can also cause many somatic diseases such as neurasthenia, decreased vision, lack of concentration, and sleep disorder. Worst of all, Internet addiction can cause conduct disorder, inducing teenagers to play truant even crime. This study still has limitations: the diagnosis of Internet addiction is only measured by self report, with no clinical assessment of disability or other sources of information. It may have an impact on the integrity of the information collection and the results accuracy. Thus, we increase the assessment of other information in further research.

\section{Conclusion}

According to the research, the mean prevalence of Internet addiction in Chinese college students was $11 \%$. Boys (16\%) have a higher rate of Internet addiction than girls $(8 \%)$. Given the rising Internet addiction rates among college students in China, effective and practical intervention measures should be taken. On one hand, government should strengthen the supervision of the Internet and provide legal protection in order to reduce the harm to college students. For example, no Internet cafes is allowed to be open within 200 meters in school, the opening hours of Internet cafes must be limited to between 8 a.m. and midnight, and an antiaddiction system should be established to limit the time spending on online games [27]. On the other hand, the university should encourage students to participate in 


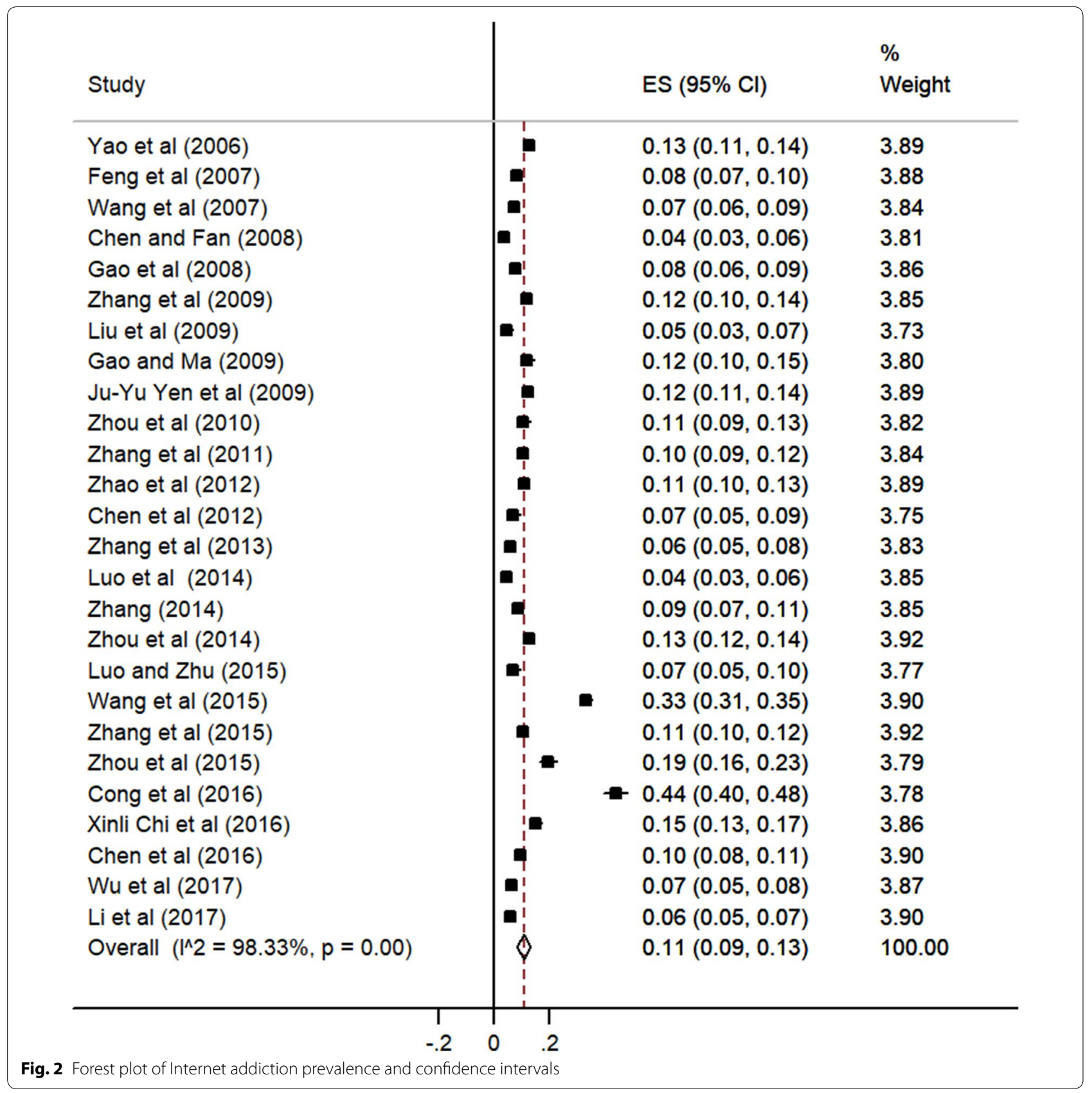

Table 2 Mean prevalence of Internet addiction among college students in different subgroups

\begin{tabular}{|c|c|c|c|c|c|c|c|c|}
\hline & \multicolumn{2}{|c|}{ Gender } & \multicolumn{4}{|c|}{ District distribution } & \multicolumn{2}{|l|}{ Scale } \\
\hline & Male & Female & South & North & East & Mid-west & Young & CIAS \\
\hline Study number & 23 & 23 & 14 & 12 & 11 & 15 & 20 & 5 \\
\hline Prevalence (\%) & 16 & 8 & 11 & 11 & 13 & 9 & 11 & 9 \\
\hline 95\% Cl (\%) & $13-19$ & $5-10$ & $8-14$ & $7-14$ & $8-18$ & $8-11$ & $8-15$ & $6-11$ \\
\hline Heterogeneity $\left(1^{2}\right)$ & 0.961 & 0.979 & 0.984 & 0.981 & 0.991 & 0.939 & 0.987 & 0.902 \\
\hline
\end{tabular}

North and South are divided by Qinling Mountains-Huaihe River Line. East and mid-west are divided by economic development level. One paper which uses CDC standard do not sort by scale

Cl confidence interval, CIAS Chen Internet Addiction Scale, Young Young Internet Addiction Scale 


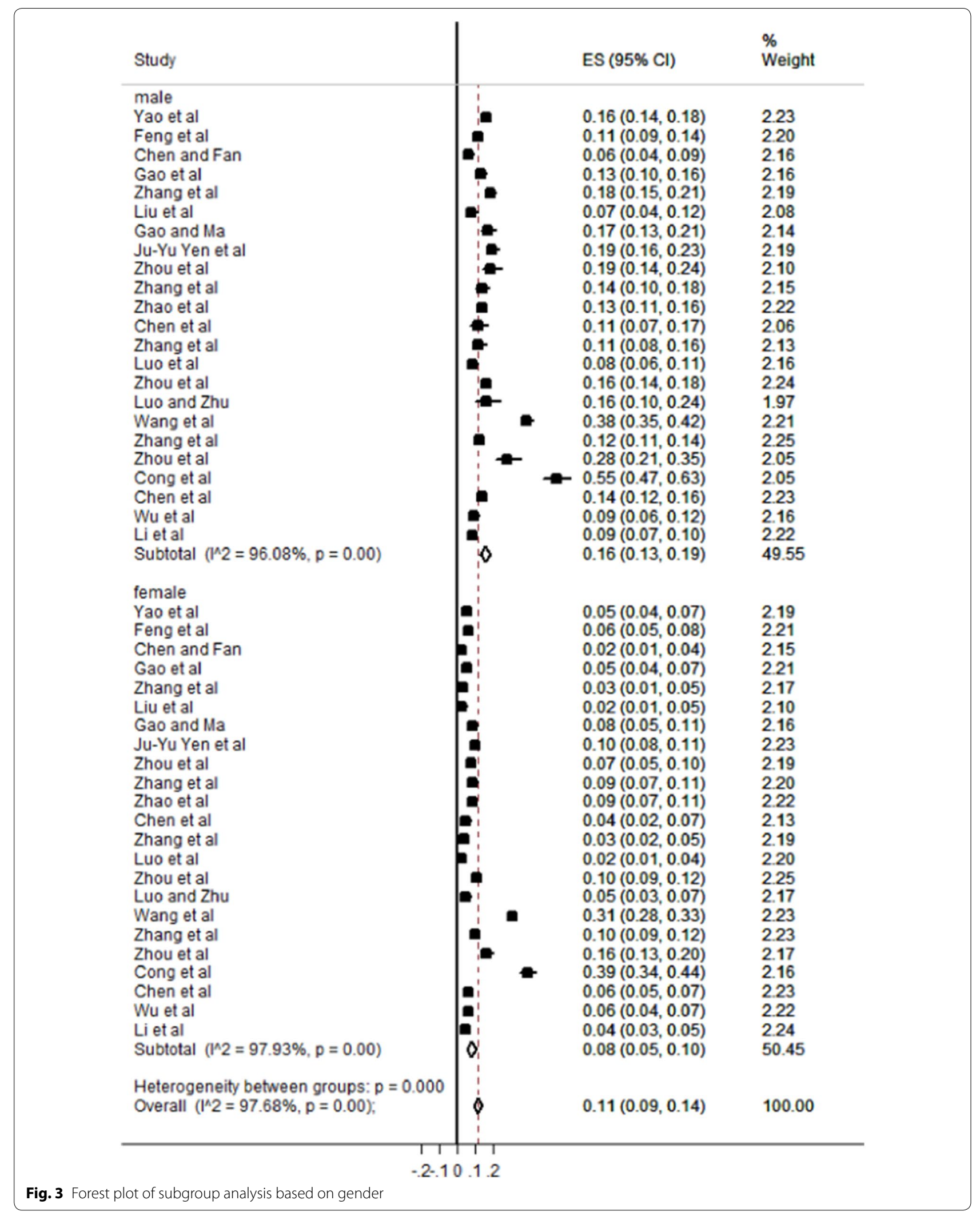


Study

ID

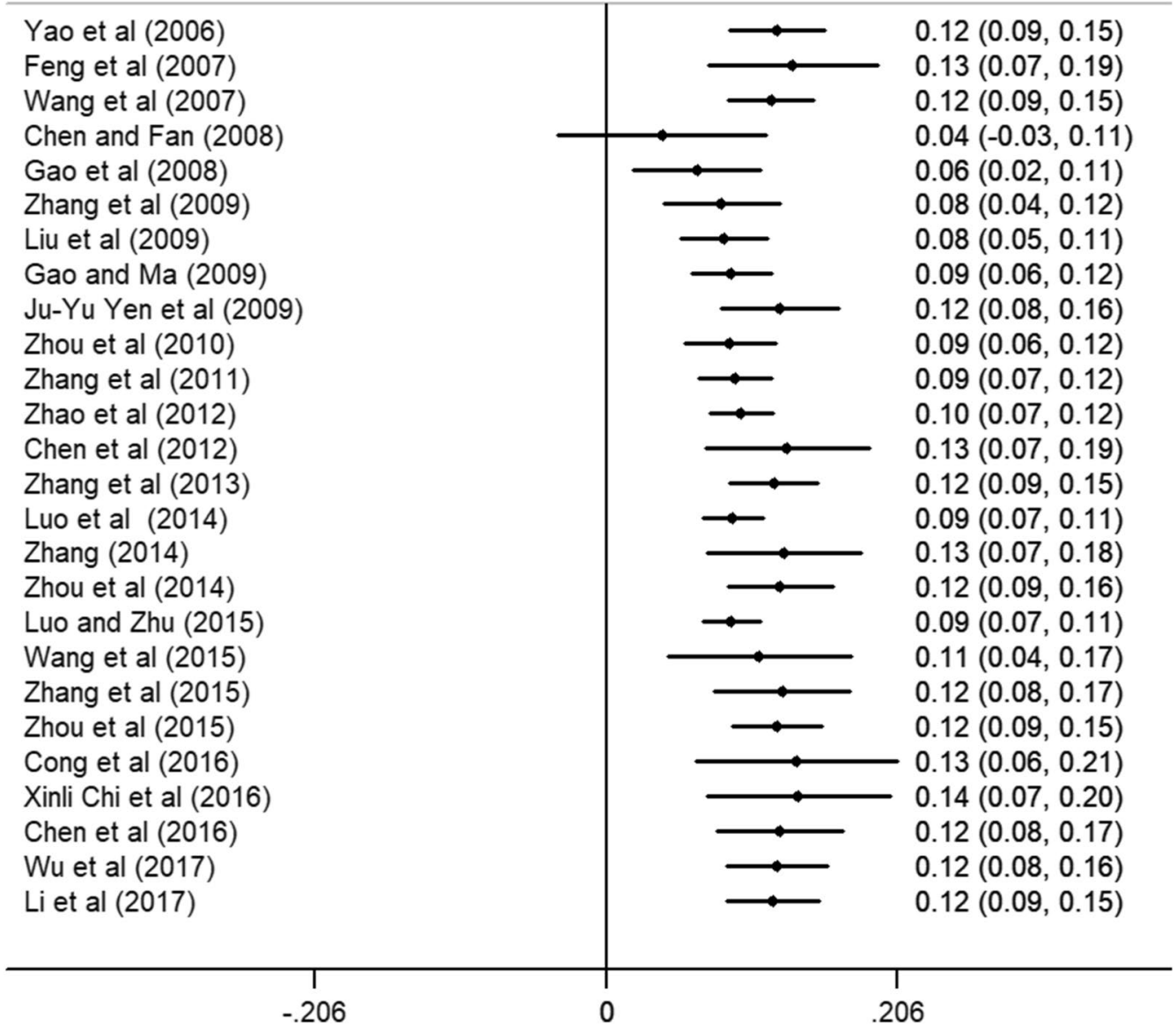

Fig. 4 Cumulative meta-analysis based on year

\section{ES $(95 \% \mathrm{Cl})$}

$0.12(0.09,0.15)$

$0.04(-0.03,0.11)$

$0.06(0.02,0.11)$

$0.08(0.05,0.11)$

$0.12(0.08,0.16)$

$0.09(0.07,0.12)$

$0.10(0.07,0.12)$

$0.13(0.07,0.19)$

$0.09(0.07,0.11)$

$0.13(0.07,0.18)$

$0.12(0.09,0.16)$

$0.09(0.07,0.11)$

$0.11(0.04,0.17)$

$0.12(0.08,0.17)$

$0.12(0.09,0.15)$

$0.12(0.08,0.17)$

$0.12(0.08,0.16)$

$0.12(0.09,0.15)$
$0.12(0.09,0.15)$

$0.08(0.04,0.12)$

$0.09(0.06,0.12)$

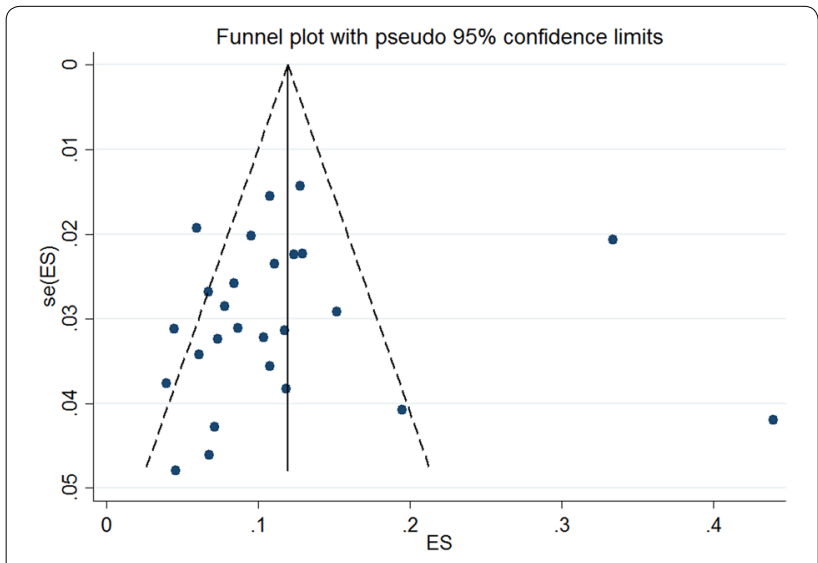

Fig. 5 Funnel plot of overall prevalence more social activities and athletic sports [28]. In addition, parents should increase communication with their kids and spend more time relieving their inner troubles as well as understanding their needs [29-31]. In my opinion, it is also important to take measures to educate society about the dangers of Internet addiction. First of all, some measures need to be taken in communities and schools where more lectures on Internet addiction can be carried out [32, 33]. Schools and communities must guide students to use the Internet when they enter school and build a good way to communicate with their parents. Secondly, parents need to set up an Internet usage plan for children to make them know the seriousness of the Internet addiction [30]. Finally, the mass media can also organize more social activities such as Internet knowledge competition and make a documentary about Internet addiction so that people learn more about the dangers of Internet addiction. The most important factor is to help people form 
a reasonable understanding of Internet addiction and change unhealthy lifestyles. It is very necessary for us to pay more attention to the social education of Internet addiction in future studies. Only in this way, Internet addiction will lessen and young people will have a healthy environment to grow up.

\section{Abbreviations}

Cl: confidence interval; CIAS: Chen Internet Addiction Scale; Young: Young Internet Addiction Scale; CDC: Chinese Center for Disease Control and Prevention; IA: Internet addiction; VI: VIP Database for Chinese Technical Periodicals; DSM-IV: Diagnostic and Statistical Manual of Mental Disorders-Fourth Edition; AHR: Agency for Healthcare Research and Quality; YDQ: Young's Internet Addiction Diagnostic Questionnaire.

\section{Authors' contributions}

As for authorship, Y-jS and TZ conceived and designed the study, Y-qW analyzed the data, LL was a major contributor in writing the manuscript. All authors contribute sufficiently to this work. All authors read and approved the final manuscript.

\section{Acknowledgements}

Not applicable.

\section{Competing interests}

The authors declare that they have no competing interests.

\section{Availability of data and materials}

The datasets used and/or analysed during the current study are available from the corresponding author on reasonable request.

\section{Consent for publication}

Not applicable.

\section{Ethics approval and consent to participate} Not applicable.

\section{Funding}

Study on prevention and cure strategies of college students' psychological and behavioral health in the perspective of preventive medicine (SK2016A0947).

\section{Publisher's Note}

Springer Nature remains neutral with regard to jurisdictional claims in published maps and institutional affiliations.

Received: 29 January 2018 Accepted: 17 April 2018

Published online: 25 May 2018

\section{References}

1. Beard KW, Wolf EM. Modification in the proposed diagnostic criteria for Internet addiction. Cyberpsychol Behav Impact Internet Multimedia Virtual Reality Behav Soc. 2001;4(3):377.

2. Craparo G, Messina R, Severino S, Fasciano S, Cannella V, Gori A, et al. The relationships between self-efficacy, Internet addiction and shame. Indian J Psychol Med. 2014;36(3):304-7. https://doi.org/10.4103/02537176.135386

3. Jelenchick LA, Becker T, Moreno MA. Assessing the psychometric properties of the Internet Addiction Test (IAT) in US college students. Psychiatry Res. 2012;196(2-3):296.

4. Ghamari F, Mohammadbeigi A, Mohammadsalehi N, et al. Internet Addiction and modeling its risk factors in medical students, Iran. Indian J Psychol Med. 2012;33(2):158-62.
5. Ac-Nikolić E, Zarić D, Nićiforović-Šurković O. Prevalence of Internet Addiction among schoolchildren in Novi Sad. Srp Arh Celok Lek. 2015;143(11-12):719.

6. Ekenze SO, Okafor $\mathrm{Cl}$, Ekenze OS, et al. The value of Internet tools in undergraduate surgical education: perspective of medical students in a developing country. World J Surg. 2017:41(3):672-80.

7. Price A. Benefits of the Internet. Br J Gen Pract J R Coll Gen Practit. 1997;47(423):664

8. Levy JA, Strombeck R. Health benefits and risks of the Internet. J Med Syst. 2002;26(6):495-510.

9. Chou WJ, Huang MF, Chang YP, et al. Social skills deficits and their association with Internet addiction and activities in adolescents with attentiondeficit/hyperactivity disorder. J Behav Addict. 2017;6(1):42.

10. Lim J, Gwak AR, Su MP, et al. Are adolescents with Internet addiction prone to aggressive behavior? The mediating effect of clinical comorbidities on the predictability of aggression in adolescents with Internet addiction. Cyberpsychol Behav Soc Netw. 2015;18(5):260.

11. Coniglio MA, Muni V, Giammanco G, et al. Excessive Internet use and Internet addiction: emerging public health issues. Igiene E Sanita Pubblica. 2007;63(2):127.

12. Berner JE, Santander J, Contreras AM, Gómez T. Description of Internet addiction among Chilean medical students: a cross-sectional study. Acad Psychiatry. 2014;38(1):11-4. https://doi.org/10.1007/s40596-013-0022-6 (Epub 2014 Jan 16).

13. Lin MP, Ko HC, Wu JY. Prevalence and psychosocial risk factors associated with Internet addiction in a nationally representative sample of college students in Taiwan. Cyberpsychol Behav Soc Netw. 2011;14(12):741-6. https://doi.org/10.1089/cyber.2010.0574 (Epub 2011 Jun 8).

14. Nestler EJ. Epigenetic mechanisms of drug addiction. Curr Opin Neurobiol. 2013;23(4):521.

15. Mun SY, Lee BS. Effects of an integrated Internet addiction prevention program on elementary students'self-regulation and Internet addiction. J Korean Acad Nurs. 2015;45(2):251-61.

16. Achnio A, Przepiorka A. Dysfunction of self-regulation and self-control in Facebook addiction. Psychiatr Q. 2016;87(3):493-500.

17. $\mathrm{Hu} J$ J, Dong $Y$, Chen $X$, et al. Prevalence of suicide attempts among Chinese adolescents: a meta-analysis of cross-sectional studies. Compr Psychiatry. 2015;61:78-89.

18. Enst WAV, Ochodo E, Scholten RJ, et al. Investigation of publication bias in meta-analyses of diagnostic test accuracy: a meta-epidemiological study. BMC Med Res Methodol. 2014;14(1):70.

19. Wang Z, Zhang $\mathrm{YH}$, Xu QQ. Several methods of published bias assessment. Chin J Health Stat. 2009;26(5):539-41.

20. Bian HY, Li Y, Li N, Liu TW. Meta analysis for Internet addiction rate among adolescents. Chin J School Health. 2016;37(1):67-70.

21. Tateno M, Teo AR, Shirasaka T, Tayama M, Watabe M, Kato TA. Internet addiction and self-evaluated attention-deficit hyperactivity disorder traits among Japanese college students. Psychiatry Clin Neurosci. 2016;70(12):567-72. https://doi.org/10.1111/pcn.12454 (Epub 2016 Oct 24).

22. Khan MA, Shabbir F, Rajput TA. Effect of gender and physical activity on Internet addiction in medical students. Pak J Med Sci. 2017;33(1):191-4. https://doi.org/10.12669/pjms.331.11222.

23. Canan F, Ataoglu A, Ozcetin A, Icmeli C. The association between Internet addiction and dissociation among Turkish college students. Compr Psychiatry. 2012;53(5):422-6. https://doi.org/10.1016/j.compp sych.2011.08.006 (Epub 2011 Oct 13).

24. Zhou XY, Xu F, Wei XL, Zhao L, Pang BH, Chang JB. Internet addiction disorder and mental health in the University Students in Yan'an City. China J Health Psychol. 2015;23(10):1506-9.

25. Luo S, Guo JZ, Hu SJ, Zhuang LH, Wang HJ. Internet addicts' behavior and influencing factors among college students. Chin J Health Stat. 2014;31(3):434-6.

26. Joiner R, Gavin J, Brosnan M, et al. Gender, Internet experience, Internet identification, and Internet anxiety: a ten-year followup. Cyberpsychol Behav Soc Netw. 2012:15(7):370.

27. Guosong S. China's regulations on Internet cafés. China Media Res. 2010;6(3):26-30.

28. Echeburua E, De CP. Addiction to new technologies and to online social networking in young people: a new challenge. Adicciones. 2010;22(2):91-5. 
29. Ko CH, Yen JY, Yen CF, et al. Factors predictive for incidence and remission of Internet addiction in young adolescents: a prospective study. Cyberpsychol Behav Impact Internet Multimedia Virtual Real Behav Soc. 2007;10(4):545

30. Lam LT. Parental mental health and Internet addiction in adolescents. Addict Behav. 2015;42:20.

31. Lin YH, Gau SS. Association between morningness-eveningness and the severity of compulsive Internet use: the moderating role of gender and parenting style. Sleep Med. 2013;14(12):1398-404.

32. Mei S, Yau YHC, Chai J, et al. Problematic Internet use, well-being, selfesteem and self-control: data from a high-school survey in China. Addict Behav. 2016;61:74-9.

33. Christakis DA, Moreno MM, Jelenchick L, et al. Problematic Internet usage in US college students: a pilot study. BMC Med. 2011;9(1):77.

34. Yao YS, Gao C, Zhou FH, Jin YL, Wang EM, Ye DQ. Epidemiological study on Internet use and Internet addiction disorder among college students. Chin J School Health. 2006;27(10):844-6.

35. Feng $C Y$, Xiong $M$, Huang LY, Luo H, Deng B. Prevalence of Internet addiction disorder and anxiety and depression Among 1497 University Students in Guizhou. Chin J School Health. 2007;28(9):801-2.

36. Wang $X Z$, Zhao $L$. The relationship between college students'Internet addiction and personality TRAITS. Chin J School Health. 2007;28(2):164-5.

37. Chen J, Fan JL. A cross-sectional investigation of College Students' Internet addiction and the analysis of its influencing factors. Acta Universitatis Medicinalis Anhui. 2008;43(3):350-3.

38. Gao Y, Li ZL, Wan BH, Li YL, Xu ZG. Investigation on Internet addiction disorder in college students. Chin J School Health. 2008;24(11):1368-9.

39. Zhang LN, Shen QJ, Yang YJ, Zhang T, Cui J, Li H. Psychological and Personality characteristics of college students with Internet addiction disorder in Ningbo. Chin Mental Health J. 2009;23(9):674-6.

40. Liu JA, Feng DX, Wang Q, Liang Y, Meng H, Jin JQ, et al. Study on status and influencing factors of Internet addiction disorder among medical college students. Chin J Soc Med. 2009;26(3):150-2.

41. Gao B, Ma HY. Research on the Internet activities and Internet addiction disorder of college students in Zhejiang Province. Chin J Health Educ. 2009;25(1):11-3.

42. Yen JY, Ko CH, Yen CF, Chen CS, Chen CC. The association between harmful alcohol use and Internet addiction among college students: comparison of personality. Psychiatry Clin Neurosci. 2009;63(2):218-24. https://doi.org/10.1111/j.1440-1819.2009.01943.x.

43. Zhou YQ, Cao JQ, Wang XL, Zhang H, Yang JW. Status of Internet addiction among undergraduates and its influencing factors. Chin Gen Pract. 2010;13(31):3528-30.
44. Zhang T, Yang YX, Bao LQ, Shen YY. An investigation of college students' Internet addiction and analysis of related factors. Strait J Prevent Med. 2011;17(6):24-5.

45. Zhao XY, Hu XB, Zhang MH, Sun YM, Zhao QG, Yang WL. Relationship of Internet addiction and depression among college students in Lanzhou. Chin J School Health. 2012;33(10):1179-81.

46. Chen SY, Zhang XF, Yang CS, Xu P, Chen JL. Study on college students with Internet addiction disorder and their personality characteristics in Wuhan City. Chin J Dis Control Prevent. 2012;16(6):544-6.

47. Zhang BH, Hu S, Sheng J. Relationship between TCM college students'IAD cases and the five-state personality theory. J Shandong Univ. 2013;51(9):105-8

48. Zhang M. The relationship between Internet addiction and mental health of Uygur College Students. Chin J School Health. 2014;35(10):1559-60.

49. Zhou XQ, Xi XL, Cheng ZH, Shen LY, Li P. Prevalence of Internet addiction disorder and mental health status among college students. Chin J Clin Psychol. 2014;22(4):619-22.

50. Luo R, Zhu DL. A study of personality traits of undergraduates with IAD. J Jiangxi Normal Univ. 2015;48(6):133-6.

51. Wang XD, Gao YS, Lin FF, Chen YC. Analysis of college students' Internet addiction status and its influencing factors in Hainan Province. Chin J Health Educ. 2015;31(12):1152-5.

52. Zhang M, Tang DW, Jiang Q, Deng SP, Zhu XY. Prevalence of Internet addiction and influencing factors among college students in Nantong. Chin J School Health. 2015;36(3):378-80.

53. Cong JN, Huang XM, Zhao YJ. An analysis and prediction of college students' Internet addiction among college students in a medical college. Chin Prim Health Care. 2016;30(8):72-3.

54. Chi X, Lin L, Zhang P. Internet addiction among college students in China: prevalence and psychosocial correlates. Cyberpsychol Behav Soc Netw. 2016;19(9):567-73.

55. Chen YJ, Li L, Hu YH, Guo XP. Relationship between parent-child communication and Internet addiction among college students. Chin J School Health. 2016;37(2):221-3.

56. Wu XS, Dong ZP, Zhu K, Li JD, Wang Q, Liu Y, et al. Analysis of Internet addiction status and influencing factors of college students. J Taishan Med Coll. 2017;38(3):263-5.

57. Li FJ, Sun J, He J, Yang BS, Wang X. Survey on the current situation of Internet addiction among college students, Henan Province, 2013. Prev Med Tribune. 2017;23(7):499-501
Ready to submit your research? Choose BMC and benefit from:

- fast, convenient online submission

- thorough peer review by experienced researchers in your field

- rapid publication on acceptance

- support for research data, including large and complex data types

- gold Open Access which fosters wider collaboration and increased citations

- maximum visibility for your research: over $100 \mathrm{M}$ website views per year

At BMC, research is always in progress.

Learn more biomedcentral.com/submissions 